\title{
Cytokine and chemokine responses to helminth and protozoan parasites and to fungus and mite allergens in neonates, children, adults, and the elderly
}

Christian J Lechner ${ }^{1 \dagger}$, Karl Komander ${ }^{1 \dagger}$, Jana Hegewald ${ }^{1}$, Xiangsheng Huang ${ }^{1}$, Richard G Gantin ${ }^{1,2}$, Peter T Soboslay ${ }^{1,2}$, Abram Agossou ${ }^{4}$, Meba Banla $^{3}$ and Carsten Köhler ${ }^{{ }^{*}}$

\begin{abstract}
Background: In rural sub-Saharan Africa, endemic populations are often infected concurrently with several intestinal and intravascular helminth and protozoan parasites. A specific, balanced and, to an extent, protective immunity will develop over time in response to repeated parasite encounters, with immune responses initially being poorly adapted and non-protective. The cellular production of pro-inflammatory and regulatory cytokines and chemokines in response to helminth, protozoan antigens and ubiquitous allergens were studied in neonates, children, adults and the elderly.

Results: In children schistosomiasis prevailed (33\%) while hookworm and Entamoeba histolytica/E. dispar was found in up to half of adults and the elderly. Mansonella perstans filariasis was only present in adults (24\%) and the elderly (25\%). Two or more parasite infections were diagnosed in $41 \%$ of children, while such polyparasitism was present in $34 \%$ and $38 \%$ of adults and the elderly. Cytokine and chemokine production was distinctively inducible by parasite antigens; pro-inflammatory Th2-type cytokine IL-19 was activated by Entamoeba and Ascaris antigens, being low in neonates and children while IL-19 production enhanced "stepwise" in adults and elderly. In contrast, highest production of MIP-1delta/CCL15 was present in neonates and children and inducible by Entamoeba-specific antigens only. Adults and the elderly had enhanced regulatory IL-27 cytokine responses, with Th2-type chemokines (MCP-4/CCL13, Eotaxin-2/CCL24) and cytokines (IL-33) being notably inducible by helminth- and Entamoeba-specific antigens and fungus-derived allergens. The lower cellular responsiveness in neonates and children highlighted the development of a parasite-specific cellular response profile in response to repeated episodes of exposure and re-infection.
\end{abstract}

Conclusions: Following repeated exposure to parasites, and as a consequence of host inability to prevent or eliminate intestinal helminth or protozoa infections, a repertoire of immune responses will evolve with lessened pro-inflammatory and pronounced regulatory cytokines and chemokines; this is required for partial parasite control as well as for preventing inadequate and excessive host tissue and organ damage.

Keywords: Helminth, Protozoa, Parasite infection, Cytokine, Chemokine, Cellular response, Age groups

\footnotetext{
*Correspondence: carsten.koehler@uni-tuebingen.de

'Equal contributors

'Institute for Tropical Medicine, Eberhard Karls Universität Tübingen,

Wilhelmstrasse 27, Tübingen 72074, Germany

Full list of author information is available at the end of the article
} 


\section{Background}

Parasitic infections are common in countries with poor hygienic conditions, where a lack of sanitation and health care facilitates the transmission and the spread of helminths like Ascaris lumbricoides, Schistosoma spp., hookworms, and protozoa like Entamoeba histolytica/ dispar [1]. Approximately two billion people are infected with helminth parasites worldwide, and some intestinal parasites may affect up to $70 \%$ of an endemic population [2]. The dispersion of parasites often overlaps, and individuals living in such areas acquire multiple infections during their lifetime and are infected concurrently with several parasite species [1]. The encounter with parasite species elicits distinct and specific immune responses in their host; cytokines and chemokines are key players which regulate and polarize cellular reactivity and antibody responses to antigens and allergens. Helminth infections associate with an initial Th1 immune response during pre-patency, while during patency a Th2-type response prevails $[3,4]$. Generally with chronic helminth parasite infections Th2-type cytokine responses predominate [5], while Th1-type cytokine responses are important for protection against protozoa, e.g. amoebiasis [6] or Plasmodium falciparum malaria [7].

A specific, balanced and, to an extent, protective immunity develops over time in response to repeated parasite encounter, with immune responses initially being poorly adapted and non-protective $[8,9]$. Such incapability can result in parasite persistence and host tissue damage as a result of inappropriate inflammatory reactivity. With repeated episodes of infection, parasite clearance, and re-infection, immune responses to foreign antigens become increasingly specific and effective; however, the development of such immunity with increasing age is not well understood. Cytokines and chemokines may enhance, suppress, and regulate the expression of immunity to intravascular and intestinal parasites; moreover, they particularly promote chemotaxis and the activation of effecter cells in parasite-invaded tissues and cells.

Monocyte chemoattractive proteins such as MCP-4 recruit effecter cells [10] and inflammatory proteins such as MIP-1delta/CCL15 and Eotaxin2/CCL24 activate eosinophil granulocytes, monocytes, and lymphocytes and so contribute to inflammation [11-13]. Cytokines released as "alarmins" and mediators of inflammation, examples being IL-19 and IL-33, may enhance Th2 type immune reactions during infections with intestinal nematodes [14-17], while IL-19 promotes chemotaxis of neutrophil granulocytes and the production of IL- 6 and TNF-alpha [18,19]. Regulatory cytokines such as IL-27 limit exacerbating Th17 and Th2 responses [20] and decrease immune pathology during malaria infection $[21,22]$. While with several cytokines and chemokines their role in parasitic infections has not yet been investigated, others like Eotaxins were found to be important for effecter cell recruitment during helminth infection.

In order to further clarify the extent to which these immune mediators become activated or suppressed during early life parasite exposure, and also with a view to later life chronic pathogen persistence, we studied the cellular production of pro-inflammatory and regulatory cytokines and chemokines in neonates, children, adults, and the elderly in response to helminth and protozoa infectious challenge and to ubiquitous allergen exposure. Distinctive production levels were observed between these groups, highlighting the development of a parasite-specific cellular responsiveness to repeated episodes of exposure and re-infection.

\section{Results}

Helminth and protozoa parasite infections in children, adults, and the elderly

The prevalence of parasite infections and parasite coinfections in children, adults, and the elderly is shown in Table 1. Free of parasite infection were $37 \%$ of the children, while $29 \%$ of adults and $21 \%$ of the elderly were negative for parasites in urine, blood, and stools. In children schistosomiasis prevailed (33\%) while in adults and the elderly Schistosoma mansoni or S. haematobium were less than $10 \%$. Hookworm infections were present in $22 \%, 26 \%$ and $34 \%$ of children, adults and the elderly, respectively, while E. histolytica/dispar was found in $22 \%, 37 \%$ and $55 \%$ of same. $M$. perstans filariasis was present only in adults (24\%) and the elderly (25\%). Multiple parasite infections were diagnosed in $41 \%$ of children, while such polyparasitism was present in $34 \%$ and $38 \%$ of adults and the elderly.

Table 1 Prevalence of parasite infections and parasite co-infections in children, adults and elderly

\begin{tabular}{cccc}
\hline & $\begin{array}{c}\text { Children } \\
(\mathbf{n = 3 5 )}\end{array}$ & $\begin{array}{c}\text { Adults } \\
\mathbf{( n = 3 9 )}\end{array}$ & $\begin{array}{c}\text { Elderly } \\
\mathbf{( n = 4 2 )}\end{array}$ \\
\hline Schistosoma haematobium/S. mansoni & $33 \%$ & $8 \%$ & $2 \%$ \\
Entamoeba histolytica/E. dispar & $22 \%$ & $26 \%$ & $34 \%$ \\
Mansonella perstans & $22 \%$ & $37 \%$ & $55 \%$ \\
Sinfection-free & $0 \%$ & $24 \%$ & $25 \%$ \\
Multiple parasite infections & $37 \%$ & $29 \%$ & $21 \%$ \\
\hline
\end{tabular}

Fresh stool samples were analyzed by microscopy for intestinal helminth eggs as well as protozoan cysts and trophozoites, and all stool samples were examined using the Kato-Katz technique. Schistosoma haematobium eggs were detected by filtration of urine samples and subsequent microscopic examination of filters, while microfilaria of Mansonella perstans were detected by microscopic analysis after gradient density centrifugation of whole blood samples as detailed in Materials and Methods. 
Cellular cytokine responses to helminth and protozoa parasite antigens in neonates, children, adults, and the elderly

Table 2 shows the antigen-inducible production levels of IL-19, IL-27, and IL-33 by umbilical cord blood cells (UCBC) and peripheral blood mononuclear cells (PBMC) (Data not shown for Asc and Ov). In neonates and children IL-19 did not change between not stimulated (Base) and antigen-stimulated UCBC and PBMC. In adults IL-19 production enhanced following Ascaris (Asc) and Entamoeba (Eh) antigens stimulation (for Eh $\mathrm{p}<0.05$ compared to Base). In the elderly, Eh, O. volvulus (Ov) and Asc antigens stimulated IL-19 responses (for Eh $\mathrm{p}<0.05$ compared to Base). The production levels of IL-27 were low in neonates and children, but IL-27 production enhanced overall in adults and the elderly, without significant differences between the groups. Spontaneous cellular release of IL-33 as well as amounts produced in response to antigens from
Eh, Ov and Plasmodium (Pf) remained low in all groups; only in response to Asc antigen were UCBC and PBMC from all four study groups found to secrete elevated amounts of IL-33 ( $\mathrm{p}<0.01$ for children and adults, $\mathrm{p}<0.001$ for the elderly; compared to Base).

\section{Cellular chemokine release to helminth and protozoan parasite antigens in neonates, children, adults, and the elderly}

Cellular production of MCP-4/CCL13, MIP-1delta/CCL15 and Eotaxin-2/CCL24 by UCBC and PBMC following stimulation with helminth- and protozoa-specific antigens is shown in Table 2 (Data not shown for Asc and Ov). Parasite antigen-induced MCP-4/CCL13 production by UCBC from neonates did not differ from spontaneous release. In children, baseline MCP-4/CCL13 production did not enhance when their PBMC were cocultured with Eh, Ov and Pf antigens. Similarly, in adults and the elderly,

Table 2 Cytokines and Chemokines in response to parasite antigens

\begin{tabular}{|c|c|c|c|c|}
\hline Cytokine/chemokine & Study group & Base & Eh & Pf \\
\hline \multirow[t]{4}{*}{ IL-19 } & Neonates & $137(0 / 301)$ & $240(77 / 404)$ & $271(9 / 449)$ \\
\hline & Children & $204(81 / 327)$ & $382(229 / 535)$ & $189(36 / 341)$ \\
\hline & Adults & $244(114 / 375)$ & $692 *(507 / 877)$ & $370(186 / 555)$ \\
\hline & Elderly & $257(128 / 386)$ & $726 *(544 / 909)$ & $319(137 / 502)$ \\
\hline \multirow[t]{4}{*}{$\mathrm{IL}-27$} & Neonates & $425(307 / 542)$ & $495(378 / 612)$ & $518(393 / 642)$ \\
\hline & Children & $557(429 / 686)$ & $666(513 / 820)$ & $501(340 / 661)$ \\
\hline & Adults & $719(503 / 935)$ & 1004 (699/1309) & $886(581 / 1191)$ \\
\hline & Elderly & $1050(898 / 1202)$ & $951(738 / 1164)$ & $932(737 / 1128)$ \\
\hline \multirow[t]{4}{*}{$\mathrm{IL}-33$} & Neonates & $52(17 / 86)$ & $67(31 / 104)$ & $32(0 / 71)$ \\
\hline & Children & $22(0 / 110)$ & $107(2 / 212)$ & $14(0 / 123)$ \\
\hline & Adults & $29(5 / 54)$ & $51(16 / 87)$ & $52(28 / 77)$ \\
\hline & Elderly & $45(28 / 62)$ & $76(26 / 125)$ & $62(36 / 88)$ \\
\hline \multirow[t]{4}{*}{ MCP-4/ CCL13 } & Neonates & $69(40 / 99)$ & $56(26 / 86)$ & $51(19 / 82)$ \\
\hline & Children & $180(120 / 240)$ & $54(0 / 126)$ & $85(40 / 130)$ \\
\hline & Adults & $129(84 / 175)$ & $14(8 / 20)$ & $135(88 / 183)$ \\
\hline & Elderly & $124(85 / 163)$ & $12(0 / 67)$ & $133(78 / 188)$ \\
\hline \multirow[t]{4}{*}{ Eotaxin-2/ CCL24 } & Neonates & $537(337 / 738)$ & $540(340 / 741)$ & $419(205 / 632)$ \\
\hline & Children & $358(264 / 454)$ & $319(201 / 438)$ & $360(235 / 486)$ \\
\hline & Adults & $1398(1223 / 1572)$ & $544 * *(297 / 790)$ & $1762(1515 / 2008)$ \\
\hline & Elderly & $1430(1262 / 1598)$ & $340 * * *(102 / 577)$ & $1405(1168 / 1643)$ \\
\hline \multirow[t]{4}{*}{ MIP-1delta/ CCL15 } & Neonates & $63(47 / 79)$ & $68(52 / 83)$ & $64(47 / 80)$ \\
\hline & Children & $46(41 / 62)$ & $56(43 / 68)$ & $41(28 / 55)$ \\
\hline & Adults & $19(12 / 29)$ & $35(24 / 46)$ & $24(13 / 34)$ \\
\hline & Elderly & $27(16 / 37)$ & $63 * *(49 / 78)$ & $26(12 / 41)$ \\
\hline
\end{tabular}

The cellular production of interleukin (IL)-19, IL-27, IL-33, MCP-4/CC13, MIP-1delta/CCL15 and Eotaxin-2/CCL24 in response to parasite antigens by umbilical cord blood cells (UCBC) and peripheral blood mononuclear cells (PBMC) from different age groups is shown. UCBC from neonates ( $\mathrm{n}=36$ ) and PBMC were isolated from children (age 10-13 years; $\mathrm{n}=35$ ), adults (18-45 years, $\mathrm{n}=39$ ) and the elderly $(50-80$ years, $\mathrm{n}=42)$, and stimulated E. histolytica antigen (Eh; $10 \mu \mathrm{g} / \mathrm{ml}), P$. falciparum antigen (Pf; $1 \times 10^{8}$ schizonts $/ \mathrm{ml}$ ) or not stimulated (Base), for 48 hours at $37 \%, 5 \% \mathrm{CO}_{2}$ and saturated humidity. Cytokine and chemokine concentrations in cell culture supernatant were determined by specific enzyme-linked immunosorbent assays (ELISA). The data are given as means with the lower and upper $95 \%$ confidence intervals (in brackets). ( ${ }^{*} p<0.05,{ }^{* *} p<0.01{ }^{* * *} p<0.001$, compared to Base). 
Eh and Pf antigens did not heighten MCP-4/CCL13 production, while Asc- and Ov-specific antigens strongly activated MCP-4/CCL13 by PBMC ( $<0.01$, when compared to Base).

Production of the pro-inflammatory Eotaxin-2/CCL24 was low in neonates and children, irrespective of the antigens used for cell stimulation. In adults, Ascaris and also Onchocerca and Plasmodium antigen extracts enhanced Eotaxin-2/CCL24 release ( $<0.01$ for Ascaris when compared to Base), while stimulation with Entamoeba antigen significantly reduced Eotaxin-2/CCL24 levels ( $<<0.01$ compared to Base). In the elderly, Eotaxin-2/CCL24 production enhanced in response to Ascaris $(\mathrm{p}<0.05)$, while depressed in response to Entamoeba antigen ( $<<0.001$ ). Highest levels of MIP-1delta/CCL15 were produced by UCBC and PBMC from neonates and children, with no significant differences between the individual antigen stimulations. Overall MIP-1delta/CCL15 production was lower in adults (mean children $62 \mathrm{pg} / \mathrm{ml}$, mean adults $25 \mathrm{pg} / \mathrm{ml}$ ); only Entamoeba antigens slightly increased MIP-1delta/CCL15 production, with this Entamoeba antigen-specific activation being significant in PBMC from the elderly $(\mathrm{p}<0.01)$. All other parasite antigens elicited MIP-1delta/CCL15 production levels around baseline levels (Table 2).

\section{Helminth antigen-induced cellular production of cytokines (IL-19, IL-27, IL-33) and chemokines (MCP-4/ CCL13, MIP-1delta/CCL15, Eotaxin-2/CCL24)}

The responses of UCBC and PBMC from neonates, children, adults, and the elderly to helminth-specific A. lumbricoides (Figure 1A) and $O$. volvulus antigens were evaluated (Figure 1B). Cellular response of IL-19, IL-27, IL-33 and MCP-4 /CCL13 to Ascaris antigen was lowest in neonates, and enhanced in children, adults, and the elderly (Figure 1A). Highest production levels of IL-19, IL-27 and MCP-4 /CCL13 were observed in adults and the elderly, without differences between the age-groups (Figure 1A). Eotaxin-2 /CCL24 production was highly elevated in adults and the elderly as compared to neonates and children $(\mathrm{p}<0.01)$. In contrast, Asc antigen-induced production of MIP-1delta /CCL15 was clearly lower in adults than in neonates and children ( $\mathrm{p}<0.01$ compared to neonates). Broad confidence intervals for IL-19 and IL-33 were observed in neonates and children for all cytokines, while confidence intervals were smaller in adults (Figure 1A).

O. volvulus antigen-specific production of IL-19 while low in neonates was found to be enhanced "stepwise" in children, adults, and the elderly (Figure 1B). UCBC and PBMC from neonates and children produced lower amounts of IL-27 than did PBMC from adults and the elderly. Mean levels of IL-33 as produced by UCBC and PBMC from neonates, adults, and the elderly were similar; only IL-33 production was decreased in children in response to Ov antigen. Production of MCP-4/CCL13 and Eotaxin-2/CCL24 was lowest in neonates and children, while PBMC from adults and the elderly produced significantly enhanced amounts of both chemokines ( $\mathrm{p}<0.01$, compared to neonates and children). In contrast, the production levels of MIP-1delta/CCL15 were highest in neonates and children, and significantly lower in adults and the elderly $(\mathrm{p}<0.01$, compared to neonates and children) (Figure 1B).

\section{Fungus and mite allergen-induced cellular production of cytokines and chemokines in neonates, children, adults, and the elderly}

Tables 3 and 4 shows the cellular production of cytokines (IL-19, IL-27, IL-33) and chemokines (MCP-4/CCL13, Eotaxin-2/CCL24, MIP-1delta/CCL15) by neonatal UCBC and PBMC in response to A. fumigatus, D. farinae and D. pteronyssinus extracts.

Allergen-stimulated production of IL-19 and IL-27 was lowest in UCBC from neonates, while IL-19 production levels were found to be enhanced in adults and the elderly (for mite allergens $\mathrm{p}<0.01$, compared to neonates). Cellular production of mite allergen-induced IL-27 was lowest in neonates but highly elevated in children. Both fungus (Af) and mite (Df) allergen induced cellular production of IL-33 were strongly elevated in children $(\mathrm{p}<0.01$ and $\mathrm{p}<0.001)$, compared to neonates, adults, and the elderly). Allergen stimulation did not induce cellular MCP-4/CCL13, Eotaxin-2/CCL24 or MIP-1 delta/CCL15 production above baseline levels.

\section{Discussion}

Immune memory and cellular effector responses against parasites may develop and take shape gradually with repeated exposure, pathogen persistence or their clearance, and also with re-infection. In the present work, cellular responsiveness in neonates and children was low while adults and the elderly had enhanced regulatory IL-27 cytokine responses, with Th2-type chemokines (MCP-4/ CCL13, Eotaxin-2/CCL24) and cytokines (IL-19, IL-33) being inducible by parasite-specific antigens and allergens.

The pro-inflammatory Th2-type cytokine IL-19 while low in neonates and children was enhanced "stepwise" in adults and the elderly; IL-19 was predominantly activated by Entamoeba and Ascaris antigens and allergens also, signifying repeated encounter with protozoan and helminth parasites and environmental allergens - such responsiveness was not yet developed in neonates and children. High IL-19 levels were observed in patients with asthma and also in an allergen-inducible asthma animal model [18]. IL-19 was found to enhance IL-1beta, IL-6, and CXCL8/IL-8 release and to attract granulocytes $[18,19]$; such mobilized and activated effecter cells may then adhere and attack tissue-infiltrating and migrating 


\section{A Ascaris antigen-induced cellular production of IL-19, IL-27, IL-33, MCP-4, MIP-1 delta and Eotaxin-2 from different age groups.}
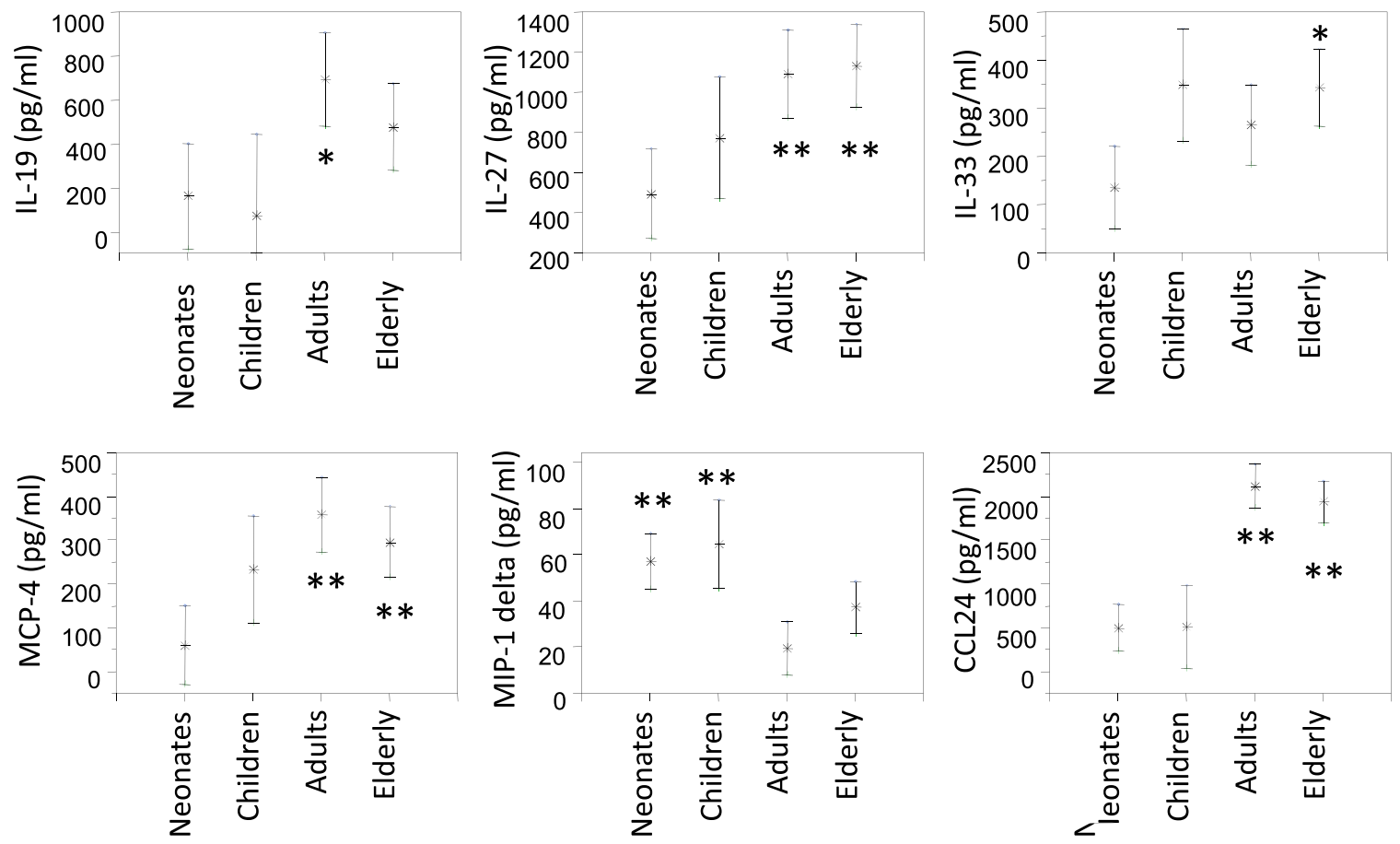

B O. volvulus antigen induced cellular production of IL 19, IL 27, IL-33, MCP-4, MIP-1 delta and Eotaxin-2 from different age groups.
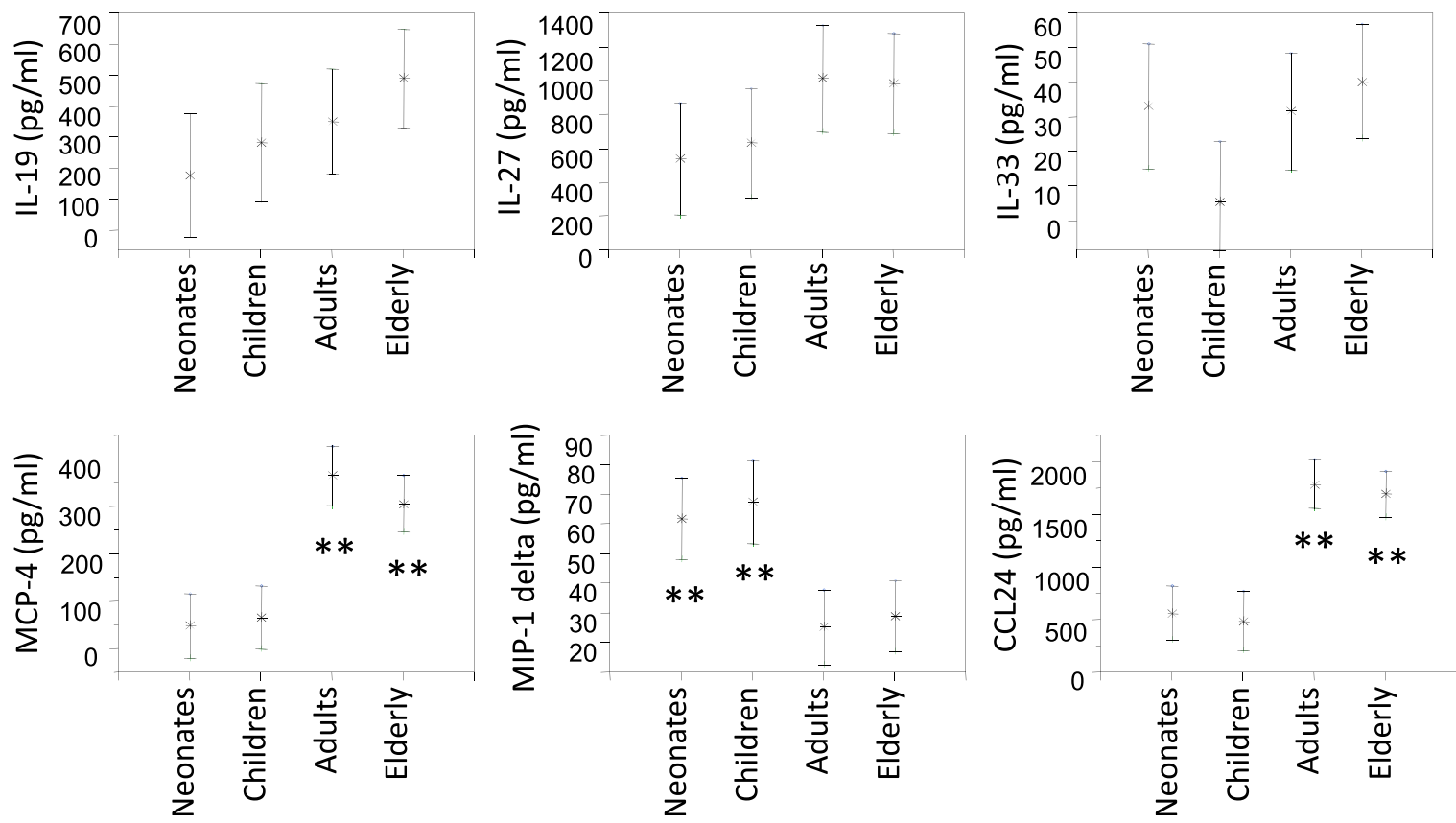

Figure 1 Cellular production of interleukin (IL)-19, IL-27, IL-33 MCP-4/CCL13, MIP-1delta/CCL15 and Eotaxin-2/CCL24 in response to $A$. lumbricoides (Asc) and O. volvulus (Ov) antigen by umbilical cord blood cells (UCBC) and peripheral blood mononuclear cells (PBMC) from different age groups is shown. A. Ascaris antigen-induced cellular production of IL-19, IL-27, IL-33, MCP-4, MIP-1 delta and Eotaxin-2 from different age groups. B. O. volvulus antigen-induced cellular production of IL-19, IL-27, IL-33, MCP-4, MIP-1 delta and Eotaxin-2 from different age groups. 
Table 3 Cytokines and chemokines in response to Aspergillus fumigatus allergen extract

\begin{tabular}{lllllll}
\hline & IL-19 & IL-27 & IL-33 & MCP-4 & CCL-24 & MIP-1 delta \\
\hline Neonates & $49(0 / 603)$ & $311(0 / 1120)$ & $62(0 / 148)$ & $0(0 / 162)$ & $283(0 / 1198)$ & $42(0 / 87)$ \\
Children & ND & $1096(957 / 1236)$ & $97^{* *}(80 / 113)$ & ND & ND & ND \\
Adults & $280(151 / 411)$ & $823(589 / 1056)$ & $34(7 / 60)$ & $116(72 / 162)$ & $1728(1474 / 1982)$ & $29(17 / 41)$ \\
Elderly & $297(172 / 424)$ & $1136(911 / 1363)$ & $56(32 / 81)$ & $119(75 / 163)$ & $1558(1315 / 1802)$ & $31(19 / 43)$ \\
\hline
\end{tabular}

** $\mathrm{p}<0.01$ in comparison to adults for IL-33.

Cellular production of interleukin (IL)-19, IL-27, IL-33 MCP-4/CCL13, MIP-1delta/CCL15 and Eotaxin-2/CCL24 in response to allergen extracts by umbilical cord blood cells from neonates (UCBC) or peripheral blood mononuclear cells (PBMC) from children (age 10-13 years), adults (18-45 years) and the elderly (50-80 years). UCBC or PBMC were stimulated with extracts from A. fumigatus (final concentration $20 \mu \mathrm{g} / \mathrm{ml}$ ) (Part A) or D. farinae ( $20 \mu \mathrm{g} / \mathrm{ml})$ and D. pteronyssinus ( $20 \mathrm{ug} / \mathrm{ml})($ Part B) for 48 hours at $37 \%, 5 \% \mathrm{CO}_{2}$ and saturated humidity. Cytokine and chemokine concentrations in cell culture supernatant were determined by enzyme linked immunosorbent assay (ELISA). The means of the brut production and the lower and upper $95 \%$ confidence intervals (in brackets) are shown. ND Not determined.

helminth larvae of Ascaris and hookworm. Furthermore, antigens of Ascaris suis and E. histolytica elicited strong chemotaxis and production of superoxide anions in neutrophil granulocytes [23,24]. IL-19 is a member of the IL-10 family; secreted by monocytes, epithelial cells and B cells [25-27], it exerts regulatory effects and, in mice, protects against colonic inflammation [28] and induces Th2 responses [29]. Inducible cellular IL-19 production in adults and elderly could therefore mirror an adaptation to intestinal protozoan and metazoan parasite challenge and allergen exposure over time. Similarly to IL-19, low amounts of IL-33 were detected in neonates; only Ascaris antigen activated IL-33 in children, suggesting early life priming by intestinal helminths. As a member of the IL-1 family, IL-33 promotes the generation of Th2 immune responses by inducing secretion of IL-4, IL- 5 and IL- 13 by T cells [30]. High levels of IL-33 were detected in patients with asthma or allergic rhinitis [31,32]. The "Alarmin" IL33 is released by injured epithelia and endothelia following hookworm infection so as to attract leukocytes to the site of inflammation [33,34]; moreover, IL-33 supports reduction and expulsion of the intestinal helminths Heligmosomoides pylorus, Trichuris muris or Nippostrongylus brasiliensis from infected mice $[17,35,36]$. A recent study [14] has disclosed the importance of IL-33 during murine hookworm infection: in IL-33 gene knockout mice infected with $N$. brasiliensis, cellular production of the Th2-type cytokine IL-13 was lessened and eosinophil recruitment reduced, and accompanied by a delayed worm expulsion in these animals.In the present work, allergens of mite and fungus activated IL-33 in children, suggesting that such increase in IL-33 reflects an initial responsiveness which, in later life and after repeated parasite exposure, is attenuated by regulatory cytokines like IL-27.

IL-27 production was low in neonates and children but gradually enhanced in adults and the elderly, with no difference between baseline and the antigen stimulation (Table 2). Mite allergen-induced production levels of IL-27 were highest in children, whereas in neonates, adults and the elderly, allergen stimulation did not induce IL-27 production above baseline levels (Tables 3 and 4). A member of the IL-12 family, IL-27 has been found to act as initiator and attenuator of immune responses [37,38], blocking both Th2- and Th17-type cytokines [37,39]. IL-27 exerts regulatory functions, mostly by inducing and regulating IL-10 and IL-17 $[37,40]$. Severe malaria tropica in children and non-healing Leishmania major infection in mice were accompanied by depressed levels of IL-27, despite high IL-10 [40,41]. IL-27R-deficient mice were able to control Toxoplasma gondii infection initially, but later succumbed due to inflammatory immune responses [42]; these mice will develop severe lung inflammation, elevated IgE levels, and eosinophilia [43]. Still, these regulatory properties of IL-27 cannot be adopted universally, as disruption of the IL-27 signaling pathway did not alter egg-induced immunopathology in an experimental schistosomiasis model [44]. While no differences in IL-27 production were observed following stimulation with parasite antigens between the age groups, enhanced IL-27 in adults and the elderly may reflect the stabilization of a regulatory cytokine network in response to repeated parasite encounter.

Table 4 Cytokines and chemokines in response to Dermatophagoides farinae/pteronyssinus allergen extracts

\begin{tabular}{lllllll}
\hline & IL-19 & IL-27 & IL-33 & MCP-4 & CCL-24 & MIP-1 delta \\
\hline Neonates & $149(39 / 260)$ & $496(330 / 662)$ & $34(14 / 55)$ & $53(28 / 79)$ & $655(448 / 862)$ & N2(70/94) \\
Children & ND & $1101^{* * *}(993 / 1208)$ & $101^{* * *}(88 / 115)$ & ND & ND & ND \\
Adults & $421^{* *(328 / 514)}$ & $799(640 / 958)$ & $36(17 / 56)$ & $83(59 / 107)$ & $1249(1059 / 1440)$ & $26(14 / 37)$ \\
Elderly & $411^{* *}(321 / 501)$ & $1077(937 / 1217)$ & $36(20 / 51)$ & $101(78 / 124)$ & $1377(1194 / 1561)$ & $25(15 / 36)$ \\
\hline
\end{tabular}

For IL-19 and IL-27: ${ }^{* *} \mathrm{p}<0.01$ in comparison to neonates, ${ }^{* *} \mathrm{p}<0.001$ in comparison to neonates; for IL-33: $* * * 0.001$ in comparison to all groups. 
Cytokines and chemokines are key players in regulating and polarizing cellular reactivity and antibody responses to pathogens and allergens. Helminth antigens induced Eotaxin-2/CCL24 and MCP-4/CCL13 production in adults and the elderly but not in neonates and children, as similarly observed for IL-19 and IL-33. Eotaxin2/CCL24 activates Th2-type cytokines and chemoattracts eosinophil and basophil granulocytes. Elevated Eotaxin-2/ CCL24 levels have been found in experimental helminth infections [45] and in acutely infected S. mansoni patients $[12,46]$, and high Eotaxin-2/CCL24 levels were associated with increased liver damage in $S$. mansoni-infected mice. Following treatment of onchocerciasis patients with ivermectin, Eotaxin-2/CCL24 and MCP-4/CCL13 enhanced suggesting that these chemokines facilitated clearance of O. volvulus microfilariae by monocytes and eosinophil granulocytes [47]. Interestingly, protozoan Entamoebaspecific antigens depressed both Eotaxin-2/CCL24 and MCP-4/CCL13 in adults and the elderly, but not in children and neonates; such depressed responsiveness might support control E. histolytica infection, as elevated levels of Eotaxins were observed in mice with persistent $E$. histolytica infection [48]. The chemokine MCP-4/CCL13 attracts granulocytes, monocytes, and T cells, and it has been proposed as a biomarker in asthma [49] being up-regulated during both Th1- and Th2-type hyperresponses [10]. In the present work, MCP-4/CCL13 and Eotaxin-2/CCL24 were not produced in neonates, but were inducible by helminth antigens in adults and the elderly - an observation pointing to the gradual expansion of the parasite-specific immune response repertoire.

In stark contrast to the above studied cytokines and chemokines, the highest production of MIP-1delta/CCL15 was found in neonates and children, whereas MIP-1delta/ CCL15 was low in adults and the elderly (Table 2). Cellular MIP-1delta/CCL15 release in response was not inducible by allergens in any group above baseline levels (Tables 3 and 4). The pro-inflammatory chemokine MIP-1delta/CCL15 attracts neutrophil granulocytes, T cells and monocytes [11]. In the present study MIP1 delta/CCL15 was inducible by Entamoeba-specific antigens only. Exposure of human monocytes to live microfilaria of Brugia malayi enhanced CCL15 mRNA expression, which was also present in IL-4 induced alternative activated macrophages [50]. With an expiring O. volvulus infection, low levels of MIP-1delta/CCL15 were detected in patients [47], while the reduced MIP1delta/CCL15 observed in adults and the elderly may represent an immune adaptation towards lessened inflammatory responses against E. histolytica. Similarly, cellular reactivity towards allergens was highest in neonates and significantly reduced in adults and the elderly.

\section{Conclusion}

In summary, helminth and protozoan antigens distinctly activated in adults Th2-type cytokines, effector cellattracting chemokines and regulatory components, notably IL-27, while such responsiveness was not yet present in neonates and children. Following repeated exposure to parasites and as a consequence of host inability to prevent or eliminate intestinal helminth or protozoa infections, a repertoire of immune responses evolves with lessened proinflammatory and pronounced regulatory cytokines and chemokines - this is required for partial parasite control and also to prevent inadequate and excessive host tissue and organ damage.

\section{Material and methods \\ Population study}

The study was conducted at the Centre Hospitalier Regional (CHR) in the Central Region of Togo and approved and authorized by the Togolese Ministry of Health (292/99/MS/CAB, 0407/2007/MMSCAB/DGS, MS/DGS/ DRS/RC/No. 220 and No. 261) and by the Ethics Committee of the University Clinics of Tübingen, Germany (No. 188/2008/BO2). A total of 152 individuals were included in the study and grouped by age: neonates $(n=36)$, children (10-13 yrs, $n=35)$, adults $(18-45$ yrs, $n=39)$ and elderly (50-80 yrs, $n=42)$. The children were all attending primary schools in suburban areas of the town of Sokodé (Prefecture Tchaoudjo). Adults were from the village of Bouzalo, near the city of Sokodé. Written consent was obtained from the childrens' parents prior to participation. Peripheral Blood Mononuclear Cells (PBMC) or else Umbilical Cord Blood Cells (UCBC) was collected from all study participants. Blood, stool and urine samples were collected from children and from adults. Umbilical Cord Blood was obtained from mothers giving birth in the Central Hospital of Sokodé. Written informed consent was obtained from all mothers after thoroughly explaining to them the procedures and risks of this study; to ensure understanding, explanations were given in the local language by the medical stuff during prenatal consultations at the CHR. Pregnant women received antiparasite treatment in line with the national health guidelines of Togo both during prenatal consultations (PC) and after partition. All pregnant women received antimalaria prophylaxis as recommended by national health guidelines - receiving either chloroquine at $300 \mathrm{mg} /$ week, which was taken until partition, or a single dose of sulfadoxine/pyrimethamine at the end of the second trimester of pregnancy as well as a further dose at the beginning of the third. In the 4th month of pregnancy, all women received antihelminth treatment (albendazole, single dose $400 \mathrm{mg}$ ) and, after partition, they were treated against intestinal protozoan parasites (metronidazole) in line with the national health guidelines. 
Isolation of peripheral blood mononuclear cells (PBMC) and umbilical cord blood cells (UCBC) and cell culture experiments

Isolation of PBMC was carried out as described earlier [51,52]. In brief, 5-9 $\mathrm{ml}$ of venous blood was collected and PBMC were then isolated using Ficoll Density Centrifugation at $340 \mathrm{~g}$ for 35 minutes. Cells were collected, washed twice in Roswell Park Memorial Institute (RPMI) media supplemented with $100 \mathrm{U} / \mathrm{ml}$ penicillin, $100 \mu \mathrm{g} / \mathrm{ml}$ streptomycin and $0.25 \mu \mathrm{g} / \mathrm{ml}$ amphotericin B (Sigma, St. Louis, MO, USA). Cells were counted and cultured at a concentration of $1 \times 10^{6}$ cells per well, supplemented in RPMI with $5 \%$ heat inactivated Fetal Calf Serum (FCS, Biochrom, Berlin, Germany). Umbilical cord blood was obtained from the placentas of healthy, full-term infants, after the placentas were delivered and separated from same. Blood samples were diluted 1:2 with RPMI (Gibco; Eching, Germany) supplemented with $25 \mathrm{mM}$ HEPES buffer, $100 \mathrm{U} / \mathrm{ml}$ penicillin and $100 \mu \mathrm{g} / \mathrm{ml}$ streptomycin, $0.25 \mu \mathrm{g} / \mathrm{ml}$ amphotericin B (as above). Umbilical cord mononuclear blood cells (UCBC) were isolated by Ficoll-Paque density gradient centrifugation at $340 \mathrm{~g}$ for $35 \mathrm{~min}$ at room temperature. UCBC were collected, washed twice in RPMI (as above) at $1400 \mathrm{rpm}$ for $15 \mathrm{~min}$ and adjusted to $1 \times 10^{6} / \mathrm{ml}$ in RPMI (as above) supplemented with 10\% heat inactivated FCS (as above). Freshly isolated UCBC or PBMC were cultured in 48 well plates in $5 \% \mathrm{CO}_{2}$ at $37^{\circ} \mathrm{C}$ and saturated humidity in the presence or absence (baseline) of the following antigens/ allergens: Onchocerca volvulus antigen (OvAg, final concentration in cell culture $20 \mu \mathrm{g} / \mathrm{ml}$, ), Ascaris lumbricoides antigen (AscAg, final conc. $5 \mu \mathrm{g} / \mathrm{ml}$ ), Entamoeba histolytica antigen (EhAg, final conc. $10 \mu \mathrm{g} / \mathrm{ml}$ ), Plasmodium falciparum schizonts (PfAg, final conc. $1 \times 10^{8}$ schizonts/ml), Dermatophagoides pteronyssinus (Dp, final conc. $20 \mu \mathrm{g} / \mathrm{ml}$ ), Dermatophagoides farinae (Df, final conc. $20 \mathrm{ug} / \mathrm{ml}$ ), Aspergillus fumigatus (Af, final conc. $20 \mu \mathrm{g} / \mathrm{ml}$ ), Candida albicans (Ca, final conc. $20 \mu \mathrm{g} / \mathrm{ml}$ ), for 48 hours at $37^{\circ} \mathrm{Celsius,} 5 \% \mathrm{CO}_{2}$ and saturated humidity. Cells and cell culture supernatant were then harvested and stored at $-20^{\circ}$ Celsius for further use.

\section{Preparation of antigens and allergens}

E. histolytica antigen (EhAg; trophozoites; strain HM-1 axenic culture) was a gift from Dr. Brigitte Walderich (formerly: Institute for Tropical Medicine, University Clinics of Tübingen, Germany). A. lumbricoides or $O$. volvulus adult worms were isolated as described previously [52], then washed in phosphate-buffered saline (PBS) before being transferred into a Ten-Broek tissue grinder and homogenized extensively on ice. The homogenate was then sonicated twice (30\% intensity) for $3 \mathrm{~min}$ on ice and centrifuged at $16,000 \mathrm{~g}$ for $30 \mathrm{~min}$ at $4^{\circ} \mathrm{C}$. The supernatants were collected and sterile-filtered
$(0.22 \mu \mathrm{m})$, and the protein concentration was then determined by BCA protein assay (Pierce, Rockford, USA). $D$. pteronyssinus (Dp), D. farinae (Df), A. fumigatus (Af) extracts were all purchased from Allergopharma (Rheinbeck, Germany). Crude antigen extracts of $P$. falciparum schizonts were kindly gifted by Dr. A. Luty and Dr. K. Brustoski (formerly: Institute for Tropical Medicine, University of Tübingen, Germany).

\section{Parasitological analysis}

Analysis for helminth and protozoan infections was carried out as previously described [51,52]. Briefly, fresh stool samples were mixed with saline, dispersed on 2 microscope slides and analyzed for intestinal helminth eggs as well as protozoan cysts and trophozoites. All stool samples were examined using the Kato-Katz technique for quantification of helminth eggs per gram of stool (helmTEST; Labmaster). Schistosoma haematobium eggs were detected by filtration of $10 \mathrm{ml}$ urine (polycarbonate membrane, pore size $12 \mu \mathrm{m}$; Whatman). Microfilaria stages of Mansonella perstans were detected by microscopic analysis after Ficoll density centrifugation. Malaria Rapid Test (OptiMal $^{\mathrm{Tw}}$, TCS Biosciences, Birmingham UK) was used to determine infection with $P$. falciparum. Children showing signs of malaria (positive thick blood smears for Plasmodium spp. and fever or Malaria Rapid Test-positive) and diarrhea were excluded from the study. None of the children presented with $E$. histolytica trophozoites ingested with red blood cells in stool samples, bloody stools or clinical signs of invasive amoebiasis.

\section{Cytokine and chemokine determination by enzyme-linked} immunosorbent assay (ELISA)

Cell culture supernatants were tested for IL-19, IL-27, IL-33, Eotaxin-2/CCL24, MCP-4/CCL13 and MIP-1 delta/CCL15 using ELISA Assay Kits (R\&D Systems). Assays were performed according to guidelines supplied by the manufacturer. Conversion of optical densities (OD) to final concentrations $(\mathrm{pg} / \mathrm{ml})$ was calculated by cytokine specific standard curves. Assay detection limits were $30 \mathrm{pg} / \mathrm{ml}$ for IL-19, $150 \mathrm{pg} / \mathrm{ml}$ for IL-27, $20 \mathrm{pg} / \mathrm{ml}$ for IL-33, $8 \mathrm{pg} / \mathrm{ml}$ for MCP-4/CCL13, $30 \mathrm{pg} / \mathrm{ml}$ for Eotaxin-2/CCL24 and $15 \mathrm{pg} / \mathrm{ml}$ for MIP-1 delta/CCL15.

\section{Statistical data analysis}

The statistical package JMP 9.0 (SAS Institute) was used to analyze significant differences between the studied groups. Significant differences in cytokine and chemokine concentrations between studied groups were determined by Analysis of Variance (ANOVA) and Tukey's Test. Due to multiple comparisons, the level of significance was adjusted by Bonferroni-Holm-method. 


\section{Competing interests}

The authors have no competing conflicts of interest to declare.

\section{Authors' contributions}

$\mathrm{CK}, \mathrm{MB}, J \mathrm{H}, \mathrm{AA}, \mathrm{CJ}, \mathrm{KK}, \mathrm{XH}$ : study proposal, data collection, study design, statistical analyses. CK, CJL, PTS, RGG: study design and coordination, interpretation of results, writing of manuscript and revision. CK, MB, AA, CJL, PTS: manuscript drafting and revision. All authors read and approved the final manuscript.

\section{Acknowledgements}

We thank all participants, but chiefly the children and their parents. For expert assistance rendered, we also thank the medical assistants, nurses and midwifes at the Centre Hospitalier Regional (CHR) in Sokodé (Togo). Our work was supported by the research program of the Bundesministerum für Bildung und Forschung (BMBF grant 01KA1008). We also acknowledge support from the Deutsche Forschungsgemeinschaft (DFG) and the Open Access Publishing Fund of Tubingen University.

\section{Author details}

${ }^{1}$ Institute for Tropical Medicine, Eberhard Karls Universität Tübingen, Wilhelmstrasse 27, Tübingen 72074, Germany. ${ }^{2}$ Onchocerciasis Reference Laboratory, Institut National d'Hygiène, Sokodé, Togo. ${ }^{3}$ Centre Hospitalier Régional, Service Pédiatrie, Sokodé, Togo. ${ }^{4}$ Centre Hospitalier Universitaire Campus de Lomé, Université de Lomé, Lomé, Togo.

Received: 15 January 2013 Accepted: 29 June 2013

Published: 15 July 2013

\section{References}

1. Supali T, Verweij JJ, Wiria AE, Djuardi Y, Hamid F, Kaisar MM, Wammes $L$, van Lieshout L, Luty AJ, Sartono E, Yazdanbakhsh M: Polyparasitism and its impact on the immune system. Int J Parasitol 2010, 40(10):1171-1176.

2. Jombo GT, Egah DZ, Akosu JT: Intestinal parasitism, potable water availability and methods of sewage disposal in three communities in Benue State, Nigeria: a survey. Ann Afr Med 2007, 6(1):17-21.

3. Grzych JM, Pearce E, Cheever A, Caulada ZA, Caspar P, Heiny S, Lewis F, Sher A: Egg deposition is the major stimulus for the production of Th2 cytokines in murine schistosomiasis mansoni. J Immunol 1991, 146(4):1322-1327.

4. Pearce EJ, Caspar P, Grzych JM, Lewis FA, Sher A: Downregulation of Th1 cytokine production accompanies induction of Th2 responses by a parasitic helminth, Schistosoma mansoni. J Exp Med 1991, 173(1):159-166.

5. Díaz A, Allen JE: Mapping immune response profiles: the emerging scenario from helminth immunology. Eur J Immunol 2007, 37(12):3319-3326.

6. Guo X, Stroup SE, Houpt ER: Persistence of Entamoeba histolytica infection in CBA mice owes to intestinal IL-4 production and inhibition of protective IFN-gamma. Mucosal Immunol 2008, 1(2):139-146.

7. McCall MB, Sauerwein RW: Interferon- $\gamma$-central mediator of protective immune responses against the pre-erythrocytic and blood stage of malaria. J Leukoc Biol 2010, 88(6):1131-1143.

8. Köhler C, Adegnika AA, Van der Linden R, Agnandji ST, Chai SK, Luty AJ, Szepfalusi Z, Kremsner PG, Yazdanbakhsh M: Comparison of immunological status of African and European cord blood mononuclear cells. Pediatr Res 2008, 64(6):631-636.

9. Köhler C, Tebo AE, Dubois B, Deloron P, Kremsner PG, Luty AJ, 1-95/C Study Team: Temporal variations in immune responses to conserved regions of Plasmodium falciparum merozoite surface proteins related to the severity of a prior malaria episode in Gabonese children. Trans $R$ Soc Trop Med Hyg 2003, 97(4):455-461.

10. Garcia-Zepeda EA, Combadiere C, Rothenberg ME, Sarafi MN, Lavigne F, Hamid Q, Murphy PM, Luster AD: Human monocyte chemoattractant protein (MCP)-4 is a novel CC chemokine with activities on monocytes, eosinophils, and basophils induced in allergic and nonallergic inflammation that signals through the CC chemokine receptors (CCR)-2 and -3. J Immunol 1996, 157(12):5613-5626.

11. Youn BS, Zhang SM, Lee EK, Park DH, Broxmeyer HE, Murphy PM, Locati M, Pease JE, Kim KK, Antol K, Kwon BS: Molecular cloning of leukotactin-1: a novel human beta-chemokine, a chemoattractant for neutrophils, monocytes, and lymphocytes, and a potent agonist at CC chemokine receptors 1 and 3. J Immunol 1997, 159(11):5201-5205.

12. Sousa-Pereira SR, Teixeira AL, Silva LC, Souza AL, Antunes CM, Teixeira MM, Lambertucci JR: Serum and cerebral spinal fluid levels of chemokines and Th2 cytokines in Schistosoma mansoni myeloradiculopathy. Parasite Immunol 2006, 28(9):473-478.

13. Dixon H, Blanchard C, Deschoolmeester ML, Yuill NC, Christie JW, Rothenberg ME, Else KJ: The role of Th2 cytokines, chemokines and parasite products in eosinophil recruitment to the gastrointestinal mucosa during helminth infection. Eur J Immunol 2006, 36(7):1753-1763.

14. Hung LY, Lewkowich IP, Dawson LA, Downey J, Yang Y, Smith DE, Herbert DR: IL-33 drives biphasic IL-13 production for noncanonical type 2 immunity against hookworms. Proc Natl Acad Sci USA 2013, 110(1):282-287.

15. Yasuda K, Muto T, Kawagoe T, Matsumoto M, Sasaki Y, Matsushita K, Taki Y, Futatsugi-Yumikura S, Tsutsui H, Ishii K, Yoshimoto T, Akira S, Nakanishi K: Contribution of IL-33-activated type II innate lymphoid cells to pulmonary eosinophilia in intestinal nematode-infected mice. Proc Natl Acad Sci USA 2012, 109(9):3451-3456.

16. Jones LA, Roberts F, Nickdel MB, Brombacher F, McKenzie AN, Henriquez FL, Alexander J, Roberts CW: IL-33 receptor (T1/ST2) signalling is necessary to prevent the development of encephalitis in mice infected with Toxoplasma gondii. Eur J Immunol 2010, 40(2):426-436.

17. Humphreys NE, Xu D, Hepworth MR, Liew FY, Grencis RK: IL-33, a potent inducer of adaptive immunity to intestinal nematodes. J Immunol 2008, 180:2443-2449.

18. Liao SC, Cheng YC, Wang YC, Wang CW, Yang SM, Yu CK, Shieh CC, Cheng KC, Lee MF, Chiang SR, Shieh JM, Chang MS: IL-19 induced Th2 cytokines and was up-regulated in asthma patients. J Immunol 2004, 173:6712-6718.

19. Hsing CH, Chiu CJ, Chang LY, Hsu CC, Chang MS: IL-19 is involved in the pathogenesis of endotoxic shock. Shock 2008, 29(1):7-15.

20. Hunter CA, Kastelein R: Interleukin-27: balancing protective and pathological immunity. Immunity 2012, 37(6):960-969.

21. Findlay EG, Greig R, Stumhofer JS, Hafalla JC, de Souza JB, Saris CJ, Hunter CA, Riley EM, Couper KN: Essential role for IL-27 receptor signaling in prevention of Th1-mediated immunopathology during malaria infection. $\mathrm{J}$ Immunol 2010, 185(4):2482-2492.

22. Rosário AP F d, Lamb T, Spence P, Stephens R, Lang A, Roers A, Muller W, O'Garra A, Langhorne J: IL-27 promotes IL-10 production by effector Th1 CD4+ T cells: a critical mechanism for protection from severe immunopathology during malaria infection. J Immunol 2012, 188:1178-1190.

23. Falcone FH, Rossi AG, Sharkey R, Brown AP, Pritchard DI, Maizels RM: Ascaris suum-derived products induce human neutrophil activation via a $G$ protein-coupled receptor that interacts with the interleukin-8 receptor pathway. Infect Immun 2001, 69(6):4007-4018.

24. Salata RA, Ahmed P, Ravdin J: Chemoattractant activity of Entamoeba histolytica for human polymorphonuclear neutrophils. J Parasitol 1989, 75(4):644-646.

25. Wolk K, Kunz S, Asadullah K, Sabat R: Cutting edge: immune cells as sources and targets of the IL-10 family members? J Immunol 2002, 168(11):5397-5402.

26. Zhong $H, W u Y$, Belardinelli $L$, Zeng $D$ : A2B adenosine receptors induce IL-19 from bronchial epithelial cells, resulting in TNF-alpha increase. Am J Respir Cell Mol Biol 2006, 35(5):587-592.

27. Hofmann SR, Rösen-Wolff A, Tsokos GC, Hedrich CM: Biological properties and regulation of IL-10 related cytokines and their contribution to autoimmune disease and tissue injury. Clin Immunol 2012, 143(2):116-127.

28. Azuma YT, Matsuo Y, Kuwamura M, Yancopoulos GD, Valenzuela DM, Murphy AJ, Nakajima H, Karow M, Takeuchi T: Interleukin-19 protects mice from innate-mediated colonic inflammation. Inflamm Bowel Dis 2010, 16(6):1017-1028.

29. Gallagher G, Eskdale J, Jordan W, Peat J, Campbell J, Boniotto M, Lennon GP, Dickensheets H, Donnelly RP: Human interleukin-19 and its receptor: a potential role in the induction of Th2 responses. Int Immunopharmacol 2004, 4(5):615-626

30. Schmitz J, Owyang A, Oldham E, Song Y, Murphy E, McClanahan TK, Zurawski G, Moshrefi M, Qin J, Li X, Gorman DM, Bazan JF, Kastelein RA: IL33 , an interleukin-1-like cytokine that signals via the IL-1 receptorrelated protein ST2 and induces T helper type 2-associated cytokines. Immunity 2005, 23(5):479-490. 
31. Liew FY: IL-33: a Janus cytokine. Ann Rheum Dis 2012, 71(Suppl 2):i101-i104.

32. Kamekura R, Kojima T, Takano K, Go M, Sawada N, Himi T: The role of IL-33 and its receptor ST2 in human nasal epithelium with allergic rhinitis. Clin Exp Allergy 2012, 42(2):218-228.

33. Moussion C, Ortega N, Girard JP: The IL-1-like cytokine IL-33 is constitutively expressed in the nucleus of endothelial cells and epithelial cells in vivo: a novel 'alarmin'? PLoS One 2008, 3(10):e3331.

34. Maizels RM, Hewitson JP, Smith KA: Susceptibility and immunity to helminth parasites. Curr Opin Immunol 2012, 24(4):459-466.

35. Hepworth MR, Danilowicz-Luebert E, Rausch S, Metz M, Klotz C, Maurer M, Hartmann S: Mast cells orchestrate type 2 immunity to helminths through regulation of tissue-derived cytokines. Proc Natl Acad Sci USA 2012, 109(17):6644-6649.

36. Wills-Karp M, Rani R, Dienger K, Lewkowich I, Fox JG, Perkins C, Lewis L, Finkelman FD, Smith DE, Bryce PJ, Kurt-Jones EA, Wang TC, Sivaprasad U, Hershey GK, Herbert DR: Trefoil factor 2 rapidly induces interleukin 33 to promote type 2 immunity during allergic asthma and hookworm infection. J Exp Med 2012, 209(3):607-622

37. Yoshida H, Miyazaki Y: Regulation of immune responses by interleukin-27. Immunol Rev 2008, 226:234-247.

38. Villarino AV, Huang E, Hunter CA: Understanding the pro- and antiinflammatory properties of IL-27. J Immunol 2004, 173(2):715-720.

39. Sturmhofer JS, Hunter CA: Advances in understanding the antiinflammatory properties of IL-27. Immunol Lett 2008, 117(2):123-130.

40. Anderson CF, Sturmhofer JS, Hunter CA, Sacks D: IL-27 regulates IL-10 and IL-17 from CD4+ cells in non-healing Leishmania major infection. $\mathrm{J}$ Immunol 2009, 183(7):4619-4627.

41. Ayimba E, Hegewald J, Ségbéna AY, Gantin RG, Lechner CJ, Agosssou A, Banla M, Soboslay PT: Proinflammatory and regulatory cytokines and chemokines in infants with uncomplicated and severe Plasmodium falciparum malaria. Clin Exp Immunol 2011, 166(2):218-226.

42. Villarino A, Hibbert L, Lieberman L, Wilson E, Mak T, Yoshida H, Kastelein RA, Saris C, Hunter CA: The IL-27R (WSX-1) is required to suppress T cell hyperactivity during infection. Immunity 2003, 19(5):645-655

43. Miyazaki $Y$, Inoue $H$, Matsumura M, Matsumoto K, Nakano T, Tsuda M, Hamano S, Yoshimura A, Yoshida H: Exacerbation of experimental allergic asthma by augmented Th2 responses in WSX-1-deficient mice. J Immunol 2005, 175:2401-2407.

44. Shainheit MG, Saraceno R, Bazzone LE, Rutitzky LI, Stadecker MJ: Disruption of interleukin-27 signaling results in impaired gamma interferon production but does not significantly affect immunopathology in murine schistosome infection. Infect Immun 2007, 75(6):3169-3177.

45. Perry CR, Burke ML, Stenzel DJ, McManus DP, Ramm GA, Gobert GN: Differential expression of chemokine and matrix re-modelling genes is associated with contrasting schistosome-induced hepatopathology in murine models. PLoS Negl Trop Dis 2011, 5(6):e1178.

46. Silveira-Lemos D, Teixeira-Carvalho A, Martins-Filho OA, Souza-Soares AL, Castro-Silva P, Costa-Silva MF, Guimarães PH, Ferraz HB, Oliveira-Fraga LA, Teixeira MM, Corrêa-Oliveira R: Seric chemokines and chemokine receptors in eosinophils during acute human schistosomiasis mansoni. Mem Inst Oswaldo Cruz 2010, 105(4):380-386.

47. Lechner CJ, Gantin RG, Seeger T, Sarnecka A, Portillo J, Schulz-Key H, Karabou PK, Helling-Giese G, Heuschkel C, Banla M, Soboslay PT: Chemokines and cytokines in patients with an occult Onchocerca volvulus infection. Microbes Infect 2012, 14(5):438-446.

48. Rojas-López AE, Soldevila G, Meza-Pérez S, Dupont G, Ostoa-Saloma P, Wurbel MA, Ventura-Juárez J, Flores-Romo L, García-Zepeda EA: CCR9+ T cells contribute to the resolution of the inflammatory response in a mouse model of intestinal amoebiasis. Immunobiology 2012, 217(8):795-807.

49. Kalayci O, Sonna LA, Woodruff PG, Camargo CA, Luster AD, Lilly CM: Monocyte chemotactic protein-4 (MCP-4; CCL-13): a biomarker of asthma. J Asthma 2004, 41(1):27-33.

50. Semnani RT, Mahapatra L, Moore V Sanprasert V, Nutman TB: Functional and phenotypic characteristics of alternative activation induced in human monocytes by interleukin-4 or the parasitic nematode Brugia malayi. Infect Immun 2011, 79(10):3957-3965.
51. Hamm DM, Agossou A, Gantin RG, Kocherscheidt L, Banla M, Dietz K, Soboslay PT: Coinfections with Schistosoma haematobium, Necator americanus, and Entamoeba histolytica/Entamoeba dispar in children: chemokine and cytokine responses and changes after antiparasite treatment. J Infect Dis 2009, 199(11):1583-1591.

52. Soboslay PT, Hamm DM, Pfäfflin F, Fendt J, Banla M, Schulz-Key H: Cytokine and chemokine responses in patients co-infected with Entamoeba histolytica/dispar, Necator americanus and Mansonella perstans and changes after anti-parasite treatment. Microbes Infect 2006, 8(1):238-247.

\section{doi:10.1186/1742-4933-10-29}

Cite this article as: Lechner et al:: Cytokine and chemokine responses to helminth and protozoan parasites and to fungus and mite allergens in neonates, children, adults, and the elderly. Immunity \& Ageing 2013 10:29.

\section{Submit your next manuscript to BioMed Central and take full advantage of:}

- Convenient online submission

- Thorough peer review

- No space constraints or color figure charges

- Immediate publication on acceptance

- Inclusion in PubMed, CAS, Scopus and Google Scholar

- Research which is freely available for redistribution

Submit your manuscript at www.biomedcentral.com/submit
C) BioMed Central 